\title{
Chapter 11 \\ Place-Making by Cows in an Intensive \\ Dairy Farm: A Sociolinguistic Approach to Nonhuman Animal Agency
}

\section{Leonie Cornips and Louis van den Hengel}

\begin{abstract}
Based on recent ethnographic fieldwork at an intensive dairy farm, this chapter examines the usefulness of posthuman critical theory for developing a new sociolinguistic approach to nonhuman animal agency. We explore how dairy cows, as encaged sentient beings whose mobility is profoundly restricted by bars and fences, negotiate their environment as a material-semiotic resource in linguistic acts of place-making. Drawing on the fields of critical posthumanism, new materialism and sociolinguistics, we explain how dairy cows imbue their physical space with meaning through materiality, the body and language. By developing a nonanthropocentric approach to language as a practice of more-than-human sociality, we argue for establishing egalitarian research perspectives beyond the assumptions of human exceptionalism and species hierarchy. The chapter thus aims to contribute towards a new understanding of nonhuman agency and interspecies relationships in the Anthropocene.
\end{abstract}

\subsection{Introduction}

Human thinkers in the western philosophical tradition have long relied upon the silencing of nonhuman animal others to confirm the exceptionalism of their own species. Since Aristotle, philosophers and scientists have defined "man" as a "rational animal" distinguished from other animals by his_-and, more recently, her or theircapacity for a special kind of thinking, variously described as self-consciousness, reason, or representational thought (Cull 2015, 19). If, as Eva Meijer asserts (2016, 73 ), in this tradition "humans are viewed as radically different from other animals," then language is commonly seen as "one of the main ways in which this difference is

L. Cornips ( $\square)$

NL-Lab, Humanities Cluster (KNAW), Amsterdam, The Netherlands

e-mail: leonie.cornips@ maastrichtuniversity.nl

L. Cornips $\cdot$ L. van den Hengel

Faculty of Arts and Social Sciences, Maastricht University, Maastricht, The Netherlands

(C) The Author(s) 2021

B. Bovenkerk and J. Keulartz (eds.), Animals in Our Midst: The Challenges

of Co-existing with Animals in the Anthropocene, The International Library

of Environmental, Agricultural and Food Ethics 33,

https://doi.org/10.1007/978-3-030-63523-7_11 
expressed." The idea that language is what makes us human, or more precisely, that the possession of language allows humans to separate themselves from nonhuman nature, including their own animality, is indeed a key component of philosophical humanism and its exclusionary conceptions of individual and collective personhood. The philosopher Giorgio Agamben $(2004,33)$ uses the term "anthropological machine" to refer to the process by which the human is defined over and against what is nonhuman or animal, thus dividing the human subject from more-thanhuman forms of sentience, sociality, intelligence and communication. The strict identification of the human with language, or what Agamben $(2004,38)$ calls an articulation between "speaking being" and "living being," is central to the functioning of the anthropological machine, that is, the ways in which humans ought to continually create themselves as speaking political beings by creating hierarchies between human, animal, vegetable and mineral species. The traditional humanist understanding of the human as a unique creature, one that rises above the natural world of animals, plants and the physical environment, thus rests on a fundamental denial that nonhuman animals might be capable of language and other forms of complex symbolic communication.

In this chapter, we wish to move beyond the assumptions of human exceptionalism and species hierarchy in order to advance an understanding of language that displaces the centrality of the human subject. Specifically, we will explore how dairy cows, as caged living beings or what sociologist Rhoda Wilkie $(2010,115)$ has called "sentient commodities," negotiate their environment as a material-semiotic resource in the production of a meaningful world. While their physical mobility is profoundly restricted by bars and fences, we will examine how dairy cows enact social and linguistic agency through complex assemblages formed by human and nonhuman bodies, materials and environments. Starting from the assumption that, within the context of dairy farming, the subjectivities of cows and humans are continuously coproduced, we want to highlight how recognizing the linguistic agency of dairy cows may allow us to resist anthropocentric understandings of interspecies relationships and to formulate a new perspective on language as a social practice of humannonhuman interaction. The central aim of this chapter, therefore, is to elaborate a radically post- or non-anthropocentric sociolinguistic approach that may help foster more egalitarian relationships to and between different species, or, as Agamben $(2004,83)$ phrases it, to bring to a "standstill" the anthropological machine that has historically articulated humanity and animality through their mutual exclusion.

The chapter has four sections. The first section examines how traditional humanist conceptions of language have structured dominant philosophical and linguistic understandings of human-animal relationships. The second section discusses the cognitive, emotional and social capacities of cows as sentient and intelligent beings, and proceeds to argue for the usefulness of posthuman critical theory for expanding the linguistic research agenda to include the study of nonhuman animal languages. This sets the stage for the third section, which discusses recent fieldwork at an intensive dairy farm in order to explore how cows, as social actors, engage in processes of linguistic place-making. Drawing, on the one hand, on recent work at the intersection of critical posthumanism and applied linguistics (Pennycook 2018) and, on 
the other, on new materialist conceptions of agency as a distributed phenomenon (Bennett 2010), we will elaborate a non-anthropocentric approach to human and nonhuman language practices. In the last and concluding section, we consider some of the implications of our findings for negotiating, or renegotiating, contemporary questions of nonhuman animal agency. As a whole this chapter argues that acknowledging nonhuman linguistic agency is essential for thinking through and responding to the specific conditions and challenges of the Anthropocene, where the advent of the human as a global geophysical force has muddled conventional distinctions between culture and nature, human and nonhuman, self and other. If, as Donna Haraway suggests, nonhuman animals "are not here just to think with," but rather they are here to "live with" (Haraway 2003, 5, emphasis added), then we must indeed embrace modes of inquiry suited to the task of confronting human and nonhuman acts of language, sociality and world-making.

\title{
11.2 Language and the Politics of Human Exceptionalism
}

The view that nonhuman animals have no speech, and therefore cannot establish themselves as ethical, juridical and political subjects, goes back at least to the ancient Greeks. In a well-known passage of his Politics, Aristotle associates the formation of political community with the supposedly unique human capacity for reasoned speech. Aristotle insists that the capacity for speech informed by reason (logos) is what separates "man", as a political animal, from the mere beasts who do not speak but simply produce sound (phonè):

\begin{abstract}
And so the reason why man is a political animal more than any bee or any gregarious animal is clear. For nature, as we often say, does nothing in vain; and man alone of the animals possesses speech (logos). The mere voice (phonè), it is true, can indicate pain and pleasure, and therefore is available in the other animals as well (for their nature has been developed so far as to have feelings of pain and pleasure and to signify them to one another), but speech, for its part, is designed to express the useful and the harmful and therefore also the just and the unjust. ${ }^{1}$
\end{abstract}

Because nonhuman animals are incapable of speech, Aristotle argues, they cannot express the civic and moral virtues that he considered essential for the wellbeing of the household and the city-state. Aristotle, as Derrida explains in The Beast and the Sovereign (2009, 343-349), thus makes a categorical distinction between human and nonhuman animals to posit an inextricable link between language and the political sphere. His philosophy therefore not only delimits political agency to certain privileged human beings - the free adult male citizens that make up the polis - but also actively excludes nonhuman animal voices from the definition of language itself.

Many later philosophers have followed Aristotle in rejecting the linguistic and cognitive abilities of nonhuman animals (Meijer 2016, 75-76). Descartes, for example, argued that animals do not think because they cannot speak: he regarded

\footnotetext{
${ }^{1}$ Aristotle, Politics, 1253a. Translation by Louis van den Hengel.
} 
nonhuman animals as machines, governed by the laws of physical matter alone and hence devoid of mind and self-awareness. ${ }^{2}$ Although he did recognize that animals such as magpies and parrots can utter words, and that dogs make noises that might resemble speech, Descartes maintained that other animals "cannot speak as we do: that is, they cannot show that they are thinking what they are saying" (Descartes 1985, 140). Heidegger, despite his phenomenological critique of Descartes, also claimed that nonhuman animals are incapable of language and therefore lack access to what he called "world-formation", that is, the ability to form true and conscious relationships with others and with their environment. According to Heidegger, nonhuman animals are unable to apprehend the world as such-that is to say, in the world-forming ways that language, understood as logos, allows for-because they are captivated by their instincts and bound to their environments. Animals do have access to the world - they are not, like stones and other inert objects, what Heidegger calls "worldless" (weltlos) - but their relationship to it is an impoverished one: Heidegger calls nonhuman animals "poor in world" (weltarm), whereas humans are deemed to be world-forming (weltbildend). Insofar as an animal is essentially absorbed in its environment (Umwelt), it cannot truly act in relation to the world (Welt) as such, or, as Heidegger puts it $(1995,239)$, an animal "behaves within an environment but never within a world."

Although Heidegger repeatedly observes that "the relation between poverty in world and world-formation does not entail hierarchical assessment" $(1995,192)$, he does nonetheless privilege human beings to the extent that, in his view, only language, by which he means human language, is capable of disclosing the world as an intelligible and meaningful place. "Language alone," he writes, "brings what is, as something that is, into the Open for the first time. Where there is no language, as in the being of stone, plant, and animal, there is also no openness of what is, and consequently no openness either of what is not" (Heidegger 1971, 73). In foregrounding human language as central to the practice of world-formation, Heidegger not only seeks to demarcate human from nonhuman animals, but also postulates a distinction between language and communication that echoes Aristotle's assumption of a fundamental difference between speech and sound, between logos and phonè, as well as Descartes' view on animals as mindless machines. For Heidegger, language is "not only and not primarily an audible and written expression of what is to be communicated" (ibid.), but rather it serves to manifest the world as such as a field of significance: an open space of possibilities, as opposed to an animal's instinctual captivation. Language, in this view, is thus what separates human being-in-the-world, or Dasein, from the being of other animals, which, as Heidegger writes, "has nothing to do with the selfhood of the human being comporting him- or herself as a person" (Heidegger 1995, 238-239).

Linguistics, no less than philosophy, has long reiterated the humanist understanding of language as a fundamental dividing line between human and nonhuman

\footnotetext{
${ }^{2}$ Most commentators attribute to Descartes the concomitant view that animals, because they cannot think, have no feelings and do not suffer pain, yet some scholars (Harrison 1992; Cottingham 2008, 163-173) have sought to contest this interpretation.
} 
animals, thus reinforcing the predominant view of language as the essence of human personhood. Aristotle's distinction between logos and phonè is still holding ground in concepts of language as either a mental or social construct in two dominant contemporary linguistic theories, namely generative grammar (Chomsky 2002, 2006) and (variationist) sociolinguistics (Labov 1994, 2001). The generative framework, advanced since the late $1950 \mathrm{~s}$ by Noam Chomsky and others, theorizes language as a human mental construct where processes of thinking and knowledge about abstract symbols are generated: a cognitive system or "inner mental tool" (Berwick and Chomsky 2016, 164) that works independently from phonetics or the speaking voice (phonè), which is assigned to language-in-use. This view consolidates the older assumption that the primary function of language is for human thought rather than for external communication. Even though language can, of course, be used to communicate with others, most of speech is inner speech, or, as Chomsky $(2002,148)$ puts it: "almost all the use of language is to oneself." In suggesting that language, defined in the narrow sense of an abstract computational system for thought, does not occur beyond the human brain, Chomsky gives a new inflection to the Cartesian understanding of language as essentially disembodied and non-social, while at the same time reinforcing the anthropocentric idea that language constitutes "a yawning chasm between what we [humans] can do and what other animals cannot" (Berwick and Chomsky 2016, 110). ${ }^{3}$

Language, in generative linguistics, is thus seen as a species-specific ability that sets human beings apart from nonhuman animal others: "When we study human language, we are approaching what some might call the 'human essence', the distinctive qualities of mind that are, so far as we know, unique to man (sic)" (Chomsky 2006, 88). Even though, in a paper coauthored for Science, Chomsky has acknowledged that "available data suggest a much stronger continuity between animals and humans with respect to speech than previously believed" (Hauser et al. 2002, 1574), he nonetheless maintains his faith in a uniquely human property of language, located either in the capacity for recursion-the ability to "generate an infinite range of expressions from a finite set of elements" (ibid.)—or in what he calls the "creative aspect" of language use, that is, the "distinctively human ability to express new thoughts and to understand entirely new expressions of thought" (Chomsky 2006, 6). ${ }^{4}$ And while Chomsky, as Donna Haraway notes, has been cautious enough to present the idea of linguistic uniqueness as "a testable hypothesis, not an assumption rooted in premises of human exceptionalism" (Haraway 2008, 373 note 44), there is no doubt that the tradition of anthropocentric thought assumed in the generative

\footnotetext{
${ }^{3}$ In his Fundamental Concepts of Metaphysics, Heidegger in a similar manner suggests that nonhuman animals are "separated from man by an abyss" (1995, 26, emphasis added). Because nonhuman animals lack language, they cannot apprehend other beings conceptually, as beings: for Heidegger, only humans are capable of grasping that which is as such.

${ }^{4}$ In this view, the linguistic ability to innovate-to form new statements that express new thoughts appropriate to but not directly caused by their immediate contexts-is considered a fundamental factor that distinguishes human language, seen as free from control by any detectable stimuli, from nonhuman animal communication, which is assumed to occur only in response to an external environment or to internal drives.
} 
framework has been a serious obstacle to investigating the linguistic, rather than communicative, abilities of nonhuman animals.

In contrast to Chomsky's non-social view of language, sociolinguistic research has built on the pioneering work of William Labov and others to theorize language as both dependent on cognition and interconnected with the workings of society and culture. ${ }^{5}$ In the sociolinguistic framework, language is understood as a social construct stemming from the need to contextualize how humans use language in interaction with others, aiming to find out how and why languages vary and change, and how (groups of) speakers employ linguistic resources to shape individual and collective identities, communities and social hierarchies. This view converges with recent approaches to language as an embodied (Bucholtz and Hall 2016), multimodal (Müller et al. 2013) and multisensory (Pennycook and Otsuji 2015) phenomenon that includes not only verbal speech but, among others, bodily gestures and facial expressions, actions, movements, sensorial practices of meaning-making through tasting, touching, seeing and smelling, as well as the mediation of embodiment by material objects, spaces and environments. Encompassing a wide range of research areas, including the social meaning of different language varieties, the role of stylization in language use, the construction of social identity categories like class and gender through language practices, bi- and multilingualism, and social norms and attitudes towards linguistic diversity, sociolinguistics has opened valuable new avenues for researchers interested in the manifold relationships between language, identity and power.

Although much sociolinguistic research remains faithful to the human as the most important user of language - in fact, the very notion that humans may use certain linguistic skills and resources is in no small part dependent on liberal humanist conceptions of choice and agency-this framework is nevertheless promising for a linguistics that wishes to be inclusive of human and nonhuman actors (Cornips 2019). By approaching language as both embodied and embedded in a variety of interactive social practices, contexts and environments, sociolinguistic studies challenge the anthropocentric understanding of a language as an exclusively verbal, decontextualized object that is completely autonomous, inaccessible from outside the mind, and therefore somehow fixed in character. In this perspective, embodiment is central to the production and interpretation of language as a form of social practice, while bodies, in turn, are themselves part of the semiotic landscape as they are "imbricated in complex arrangements that include nonhuman as well as human participants, whether animals, epidemics, objects, or technologies" (Bucholtz and Hall 2016, 186).

Broadening up the concept of language (grammar) to include multimodal and multisensory practices of meaning-making allows us to foreground nonhuman semiotic capacities, including specific sensorial abilities such as olfactory ones for cows and dogs, as language-specific grammatical means. It thus provides a useful framework to analyze differences between and among human and nonhuman animals

\footnotetext{
${ }^{5}$ Neither generative nor sociolinguistic theory has questioned the legitimacy of each other's discipline, yet attempts to integrate both have not been successful (Cornips and Gregersen 2016).
} 
in terms of grammatical possibilities and expressions instead of simply ascribing deficiencies to the latter (Kulick 2017, 373). For example, if a cow in an indoor dairy farm steps back and withdraws her face through the iron bars when humans approach her, this bodily movement combined with head positioning, gaze direction and the sound of the moving iron bar may be analyzed equally to how human animals phrase negation as in the sentence do NOT approach me (Cornips and van Koppen 2019). Further below, we will demonstrate how recent scholarship produced at the intersection of sociolinguistic theory and critical posthumanism will allow us to take the study of language beyond the speaking human subject and into the more-than-human material world. But first, let us discuss the linguistic abilities and communicative competence of cows in more detail. What can a non-anthropocentric approach to language contribute to our understanding of the ways in which cows speak to each other and to humans? And how can this understanding, in turn, help us confront, and respond to, the enabling and constraining conditions under which dairy cows, as speaking beings, participate in the formation of a meaningful world?

\subsection{Cows as Social and Linguistic Beings}

Human thinkers, as we have seen, have produced the idea of language as a uniquely human trait by categorically marginalizing nonhuman animal speakers, denying them recognition as linguistic subjects. But, as Eva Meijer suggests, learning about how other animals use language "can help us understand them better, and build new relations with them; challenging an anthropocentric view of language can help us see animals of other species, and their languages, differently" (Meijer 2016, 74). Recent research into how different animal species communicate, ranging from birds and bees to whales, apes and cephalopods, indeed suggests that there may not be a "sharp divide between human language and nonhuman communicative systems" (Evans 2014, 258; see also Meijer 2019). This does not mean that human and nonhuman forms of communication are the same, but, as Alastair Pennycook $(2018,82)$ notes, "it is an argument against human exceptionalism." In this chapter, we take the view that both human and other animals create meaning through language conceptualized as a social, spatial and artefactual resource. By theorizing language in terms of material-semiotic assemblages and spatial repertoires (Pennycook 2017), we wish to avoid an anthropocentric definition of language that not only a priori excludes nonhuman animals, but also neglects all other aspects of language beyond the "distinctive qualities of mind" so often privileged in philosophy, linguistics and cognitive science.

Cows, including domestic dairy cows, have distinct personalities and stable personality characteristics and have a clear capacity to lead rich and socially complex lives. Measured assessments of cows' cognitive, emotional and social abilities provide scientific support for what people familiar with cows already know, namely that cows demonstrate intelligence, experience a range of emotions and display a high level of social complexity, including social learning, in ways that human animals can 
recognize (Marino and Allen 2017; Colvin et al. 2017). When given the opportunity, cows form strongly bonded social groups, with mother cows and calves sharing an especially powerful emotional connection that, in part, depends upon the possibility for the mother to be able to lick her child for several hours after birth (Marino and Allen 2017, 484). Cows are competent learners and possess both short- and long-term memories: they are capable of discriminating between different objects, colors and geometric shapes, and are able to learn and recognize individual differences among humans, as well as conspecifics, under a variety of circumstances. ${ }^{6}$ These abilities show that cows do not merely respond to external stimuli but engage in the formation and categorization of mental concepts (Colvin et al. 2017, 7). Moreover, cows display emotional reactions to their own learning and in response to each other's feelings, which has been suggested to reflect sophisticated levels of psychological capacities such as self-awareness and empathy (Hagen and Broom 2004; Marino and Allen 2017, 482-483). ${ }^{7}$

As social mammals, cows depend on each other for interaction and emotional support; social isolation therefore inflicts great stress on them, as does the immediate, and life-long, postpartum separation of mothers and calves in intensive dairy farming. In commercial settings, where human-cow relations are deeply instrumentalized and commodified, the possibilities for cows to express species-appropriate behavior are severely compromised by periods of confinement in indoor housing, health problems due to higher milk yields and distress caused by various forms of social separation. As caged living beings, with little or no opportunity to escape their exploitation by humans, cows raised for food in factory farms experience "unnatural conditions from birth to slaughter" (Marino and Allen 2017, 474), including procedures that cause severe pain and suffering such as dehorning and disbudding. In these circumstances, where young calves are raised individually and cows are killed before their time, social bonding formation is extremely difficult to establish and maintain (McLennan 2013), which has devastating consequences for their wellbeing and welfare. It is decidedly problematic, then, that most research into the lives of cows is done within the framework of their use as "livestock" for human consumption. As the scientific literature on cow psychology and behavior is dominated by an applied science perspective mainly relevant to human practices of intensive farming (e.g. training cows to use automatic feeders) (Marino and Allen 2017, 475), there is a felt need to understand, and relate to, cows on their own terms.

\footnotetext{
${ }^{6}$ In one study, cows have been demonstrated, within a few training sessions, an ability to discriminate photographs of different cows' faces from faces of other species. A later study has shown that heifers can differentiate between two-dimensional facial images of familiar and unfamiliar cows, treating these images as mental representations of real individuals (Marino and Allen 2017, 478-479). So far, there is no knowledge yet on social learning from humans or the use of human-given cues in cattle (Nawroth et al. 2019, 5).

${ }^{7}$ Emotional reactions to learning in cows have to do with "the positive emotions and excitement that go with realizing one is controlling a situation" (Marino and Allen 2017, 482). This does not merely show that cows understand the causal relation between accomplishing a task and receiving a reward, but rather it suggests that they learn to experience task solving as intrinsically rewarding by adopting "an emotional perspective on their own agency" (Hagen and Broom 2004, 212).
} 
While it is undeniable that dairy cows are always already caught in the anthropological machine of industrial animal production - an "apparatus" (Despret 2008) that essentially prevents them from experiencing a full quality of life-we do believe that an inquiry into how dairy cows make use of language, conceptualized in a nonanthropocentric manner, can help human animals to get to know cows better and to understand them as "the someones they actually are" (Colvin et al 2017, 3). This will, in turn, allow us to respond to the question of nonhuman animal agency in new ways that not only serve to challenge established structures of species hierarchy, but also entail a fundamental rethinking of how agency is enacted in and through language as a practice of human-nonhuman sociality. In the context of what has been termed the "cage age," it is routinely assumed that the restrictive and monotonous captive environments in which domesticated animals usually live, will "limit the frequency and diversity with which [their] agency is expressed" (Špinka and Wemelsfelder 2011, 34). Yet, as we will demonstrate below, these same restrictive conditions can, paradoxically, also give rise to new modes of linguistic agency and resilience, revealing the copious ways in which dairy cows, as speaking beings, orient themselves towards the world.

Dairy farmers bring their own perspectives on how cows, as social and sentient beings whose freedom of movement is nevertheless severely restricted, give meaning to their physical environment and negotiate their housing conditions. A female dairy farmer based in the south of the Netherlands recently provided this chapter's first author with a hand-written letter with some of her thoughts in preparation of an interview addressing how cows and farmers communicate with each other. ${ }^{8}$ She wrote:

A true story: Cows are herd animals and they have a leader who will inform the others what to expect. Mientje was always the first waiting by the fence for the farmer to collect them [from the meadow] to be milked. The cows would first be treated to snacks in the barn which is a feast. They might become so impatient as children, and Mientje always watched carefully $\overline{\text { how }}$ the farmer would unlock the fence. An iron slide bolt. For days she would be licking that bolt and the farmer assumed she liked the taste of it, but actually she was practicing how to accomplish that [unlocking the bolt] by sliding it across with her tongue bit by bit long enough, and yes the farmer stayed away for too long and she opened the fence by herself, moved a bit backwards so that the fence could open further and so she managed to steer all the cows to the barn where there were no snacks present since it was no milking time yet. The barn was an overshitted barn that first had to be cleaned with very restless cows back in the meadow. The blacksmith made a new bolt.

Mientje, in the narrative above, is clearly positioned as an actor, even though her actions arise from within a state of unfreedom that makes it difficult, if not impossible, to draw sharp boundaries between action and passion, between doing and suffering. Seemingly functionless activities such as repetitive licking and/or biting of non-food objects, including bars and fences, are common stereotypic behaviors in captive ungulates and are caused by the frustration of natural behavior patterns

\footnotetext{
${ }^{8}$ The interview anticipated in the letter took place at the second farm (Farm 2) in the south of the Netherlands where the first author conducted her field research which is further discussed below. This interview took place on 15 February 2019 and is not discussed further in the current chapter.
} 
or by repeated attempts to deal with some problem (Bergeron et al. 2006). Tongue rolling, object licking and biting at fences-important indicators of compromised animal welfare - are especially prevalent among intensively housed cattle, as they are routinely deprived of the freedom to pursue natural patterns of grazing and rumination (Moran and Doyle 2015, 47). Nevertheless, it is also clear that Mientje's actions are not at all inconsequential or meaningless. On the contrary, by unlocking the bolt, leading the herd to the barn in the expectation of finding some snacks and by shitting the barn when they find nothing there, Mientje and the other cows not only spur their humans into action (cleaning the barn, producing a new bolt) but also engage in linguistic acts of place-making by transforming their shared living space into a site for negotiating, or renegotiating, the semantics of power, resistance and belonging.

A place, in the sociolinguistic sense, is not simply a fixed geographic location but rather a changeable site of symbolic meaning as well as a material assemblage of objects or things that mediate social processes and relationships (Johnstone 2011; Cornips and de Rooij 2018a; Peck et al. 2019). Place-making, then, involves the assigning, through interaction and other forms of connectivity, of social meanings to physical (and, increasingly, digital) spaces, thereby "creating places that are perceived as the basis of belonging" (Cornips and de Rooij 2018b, 7-8). In contrast to other branches of linguistics where languages are seen as "naturally" anchored to specific spaces - a view that only holds if a language is conceptualized as a monolithic and identifiable object detached from real-time practices - a sociolinguistics of place takes a practice-based approach focused on speakers and their activities. This shifts the focus from the linguistic system or structure to a whole range of situated practices in which speech is produced, so that what is typically labelled as $a$ language is reconceived as a linguistic resource that only becomes socially meaningful in combination with other material-semiotic resources distributed across people, places and environments (Pennycook 2017).

Although previous sociolinguistic research has conceptualized place-making primarily or even exclusively in terms of human practices and institutions, we suggest that other animals, like cows, also engage their senses, thoughts and emotions in the material-semiotic production of the world as a meaningful place. This entails a clear break away from the previously discussed humanist conceptualizations of language as a computational system located exclusively within the human mind-a view on language which, as we have seen, is itself informed by a desire to place the human above all other animals - and steers us towards an understanding of language as a distributed phenomenon, an emergent property deriving from the interactions and interrelations between human and nonhuman actors, including spatial resources and things usually seen as inanimate (Cowley 2011; Pennycook 2017). This shift in thinking corresponds to the critical posthumanist "turn" that has been put on the linguistic research agenda recently by Alastair Pennycook, who urges us "not just to broaden an understanding of communication but to relocate where social semiosis occurs" (Pennycook 2016, 446). Once we acknowledge that, as Pennycook $(2018,51)$ notes, "linguistic and other semiotic resources are not contained in someone's head, nor just choices available within a speech community, but are spatially distributed," 
we can begin to explore how dairy cows, such as Mientje, engage in linguistic placemaking in relation to other cows, farmers, fences, iron bars and spaces such as barns and meadows, as well as through embodied acts of looking, smelling, licking, walking, eating, defecating, playing and listening.

\subsection{Linguistic Place-Making in an Intensive Dairy Farm}

In the previous section, we suggested that cows, as sentient and intelligent beings, engage their cognitive, emotional and social abilities in practices of linguistic placemaking. Just as for people, we assume that the formation of meaningful bonds between cows and a place is "a powerful factor in social life... and is often based on the social relationships that are enacted in a place" (Schieffelin 2018, 35). In this section and the next, we will examine in more detail how intensively housed cows engage in place-making through language, understood as a distributed phenomenon emerging from within "material webs of human and nonhuman assemblages" (Pennycook 2017, 279). Drawing on recent fieldwork at an intensive dairy farm, we seek to demonstrate how in this context linguistic place-making occurs through multimodal and multilingual repertoires where human and nonhuman bodies, materials and environments come together in co-shaping motion. We will pay special attention to the questions of material and nonhuman animal agency, not merely because "processes of place-making and place itself are always sensible to power dynamics and asymmetries" (Schieffelin 2018,34), but also because these questions are crucial for thinking through the challenges of human-nonhuman coexistence in the current context of the Anthropocene.

First, a cow becomes connected to her place as a "territory of knowledge" (Schieffelin 2018, 30, citing Århem 1998) through her verbal practices. While cattle vocalizations are often proposed as indicators of animal welfare, scientific analysis of naturally occurring contact calls produced by crossbred beef cows and their calves have provided insight into the acoustic structure and information encoded in these vocalizations. One study showed that calf calls encode age, but not sex, and are produced $(\mathrm{F} 0=142.8 \pm 1.80 \mathrm{~Hz})$ when separated from their mothers and preceded suckling (Padilla de la Torre et al. 2015, 58). Also, indoor housed calves produce individually recognizable calls to their mothers and vice versa whereas indoor housed cows signal verbally that they are hungry, sexually aroused, and experience milking delay in distinctive ways (Jahns 2013, 247). Thus, although cow sounds may be meaningless to most human animals, they constitute meaningful signs recognizable by mother cows and their calves, as well as by fellow cows as a sociolinguistic community of practice.

Further, cows establish place-making through visual, auditory, olfactory, gustatory and tactile practices, as well as through creative behavior such as play. Sight is a cow's most dominant sense, with a field of vision of at least $330^{\circ}$ and a fine eye for details. Cows pay more attention to moving objects than ones that remain still, such as bars, and they are often "spooked" by sudden movements. A cow's hearing 
is better than that of horses, but she is less able to locate sounds compared to goats, dogs and humans. She has an acute sense of touch, which enables her to enjoy some forms of tactile contact, such as scratching behind the ears, but it also means that the conditions of industrial farming cause her considerable pain. Olfaction plays an important role in cows' social lives, and there is evidence that they can detect the scent of stress hormones present in the urine of fellow cows (Marino and Allen 2017, 475-476). Cows engage in all forms of play found in mammals, including gamboling and running, playing with objects such as balls and social play with members of other species. While play is an important indication of an animal's pleasure, curiosity and capacity to innovate, and as such it "forms the basis for complex object-related and social abilities" (Marino and Allen 2017, 481), play behavior in captive animals is also dependent on their housing conditions; for example, being released from confinement will increase the frequency of movement-based forms of play such as galloping and bucking. In what follows, we will discuss specific examples from field research to demonstrate how dairy cows can mobilize these structural constraints to imbue their environment with linguistic meanings and thus negotiate their positioning within an anthropological machine that is, by and large, designed to deprive them from the opportunity to speak.

\subsubsection{The Fieldwork Site}

From May 2018 through 15 February 2019, this chapter's first author conducted fieldwork in three dairy farms in the south and west of the Netherlands and in one small dairy farm in Norway. The observations presented in this chapter are based on data collection at Farm 1 in the south of the Netherlands, where the first author spent several weeks during her holidays in May and which subsequently became the site for three days of ethnographic observation, including two days of gathering audio- and video recordings. ${ }^{9}$ The dairy farm counts about 150 adult cows, heifers and calves. The dairy cows are milked by robots, while an automatic feeder takes care of pushing the food towards them, minimizing embodied practices between farmers and cows. A small camp site and some holiday apartments accompany the farm, as so often in the south. Many tourists, children in particular, seek contact with the newly born calves, as well as with the older calves and heifers to be discussed below, petting them and speaking to them. Feeding the newly born calves, who are housed individually in fiberglass cages outside the barn, is an especially popular activity among the human

\footnotetext{
${ }^{9}$ The fieldwork took place on 25 July (observation), 26 July and 17 August 2018 (audio- and video recordings). A written and signed consent form by the owners of Farm 1 was obtained abiding by the guidelines for research as stated in the protocol of the Ethics Assessment Committee Humanities of the Radboud University Nijmegen and adopted by the Royal Academy of Arts and Sciences (KNAW). From the perspective of establishing egalitarian research methods for interspecies collaboration, there is a need to examine how to receive permission from the nonhuman animals under study, while at the same time one should interrogate how the bioethical framework of "informed consent" is set up through human-centred discourses of rational agency and choice.
} 
visitors. During the on-site observations, the cows would often reach through the bars and fences to touch the farmers, tourists and field worker through licking and nuzzling. They would also establish contact through nonverbal interactions such as eye gaze and body positioning, as well as by using language in the form of rumbling, calling, hooting, sniffing and coughing. These practices would happen frequently, even though neither humans nor cows were able to traverse to sharing space with each other directly.

Farmers usually assign dairy cows to fixed places in artificial groupings based on their age without male peers, revealing extreme power asymmetries between cows and humans. In the farm under observation, cows are assigned to eight distinct places differentiated by age: new-born calves, older calves up until a few weeks of age, young heifers, older and oldest heifers, dry cows (pregnant cows), and dairy cows. As noted, new-born female calves are separated from their mothers immediately after birth and isolated in fiberglass enclosures, so-called "igloos," for about three weeks. In Farm 1, these igloos are placed in the open air facing the dairy cows in the open barn. After this period, the somewhat older calves are housed together with their age mates in igloos holding up to four or five animals, positioned sideways to the open barn so that visual contact with the older cows is much more restricted. Growing older, the calves are placed in the so-called jongveestal (young cattle barn) in four different age groups (see Fig. 11.1). The dry cows are housed in a separate space and the dairy cows reside in the large open barn that also contains three milking robots. In spring and summer, the dry cows and dairy cows can graze in the meadow during the day and, when it is very hot, during the late evening and night. The assignment to specific physical places in distinct housings prevents the calves, heifers and cows from forming a natural herd that would include a matrilineal social structure with strongly clustered networks and many non-random attachment and avoidance relationships (Marino and Allen 2017, 488). It also prevents the younger ones from engaging in processes of cognitive and social learning, and deprives them from being comforted by older conspecifics, including mother cows.

The fieldwork took place in the jongveestal, where audio and video recordings were made while observing the calves and heifers. The jongveestal is an oblong building, about twenty by ten meters, with half bowed windows, touching the house where the farmer's family lives. It is the oldest barn on site with a main entrance in the middle of the long front side and a full opening at one of the short sides. The cattle stay indoors: their day includes some combinations of eating, lying and

\begin{tabular}{l|l|l|l|}
\hline$\leftarrow$ & \multicolumn{3}{|c|}{ 20 meters } \\
\hline Section 1 & Section 2 & Section 3 & Section 4 \\
\hline $\mathrm{n}=12$ & $\mathrm{n}=9$ & $\mathrm{n}=7$ & $\mathrm{n}=8$ \\
\hline \\
$\begin{array}{l}\text { Calves (older than three weeks) } \\
\end{array}$
\end{tabular}

Fig. 11.1 Jongveestal (“young cattle barn”), housing 36 calves and heifers (Friday 17 August 2018, 2.30-6 p.m.) 
standing. The oldest heifers were about one year old during the fieldwork. ${ }^{10}$ In May, swallows would fly in and out to take care of their new-born in the many nests they had fabricated under the beams of this old building. The floor of the jongveestal consists of cubicle divisions for calves and heifers to lie down and stand up (see Picture 11.3 below), while in-between the cubicles, they can stand or walk on discrete beams where feces and urine pass.

In the jongveestal, the calves and heifers $(n=36)$ were spatially positioned in four sections divided by iron bars, as illustrated in Fig. 11.1. The calves and heifers in the jongveestal are thus profoundly restricted in their mobility-much more so than the adult cows who are able to graze in the meadow, but less than the new-born calves confined to the small igloos. Consequently, from birth onwards throughout their lives, calves, heifers and dairy cows - either individually or with same-sex and age mates - are confined to human-made physical spaces. How, then, do they manage to assign their own meanings to the restricted environment in which they are placed?

\subsubsection{Place-Making Through Practices of Sociality and Multilingualism}

The housing conditions of the jongveestal not only restrict mobility but also limit the visual, auditory, olfactory, gustatory and tactile practices that calves and heifers may display under less restrictive conditions. This significantly affects their modes of sociality and processes of belonging: calves and heifers cannot touch and/or allogroom each other cross-sectionally; a lack of daylight hinders optimal vision and the walls obstruct a far vision; the sound of tractors may penetrate; calves and heifers are dependent on the farmer for how to lie down as well as for when, what and how to eat (with no attention for individual food preferences); ventilation is often not optimal so that calves and heifers, whose sense of smell is far superior to that of humans, deal with omnipresent scents of ammonia, carbon dioxide, methane and hydrogen sulfide (Vallez 2013, 12); and the beams on the floor, often slippery due to feces and urine, impede playing and running (see Picture 11.3). Limited space allowance furthermore makes it difficult to maintain a preferred distance to neighbors with whom the individual likes to bond or not. The spatial distance that cows establish between each other is affected by their relationship and proximity might indicate the existence of a social bond (McLennan 2013, 26). Under more natural conditions, cows seem to engage with particular individuals with whom they prefer to spend their time, creating voluntary bonds while grazing and lying together in close proximity (McLennan 2013, 49-50). In the captive environment of the jongveestal, however,

\footnotetext{
${ }^{10}$ During her holidays in May, the first author frequently visited the jongveestal since there was one heifer who was very much looking for contact with human animals. She was positioned near the main entrance and would nearly jump towards the author to put her head on her shoulder. This extravert expression of contact seeking behavior might be interpreted as indicative of a willingness to engage in interspecies collaboration.
} 
a calf or heifer who is a non-preferred partner may stand, lie down or eat in closer proximity than would naturally occur, which may lead to feelings of uneasiness and has been suggested to have negative consequences for animal welfare (McLennan 2013, 52).

How, if at all, do calves and heifers in the jongveestal create sociality under these conditions? And how is this sociality mobilized in and through material-semiotic practices of place-making? Fieldwork observations show that the calves and heifers in their cubicle divisions (see Fig. 11.1) may not show any sign of interaction or connectivity, thus is it not self-evident for individuals who are placed in a restricted space to construe it together as a social place. Picture 11.1 shows an example: four older calves stand in the second section of the jongveestal. Although they share a restricted physical space, their body positioning does not reveal any form of coshaping the act of standing together. The calves position their bottoms to each other, taking diverging positions, avoiding eye contact and body contact. Although the calves in the right corner seem to align sideways, there is no form of interaction. Their bodies don't touch and while the calf in the middle bows her head, the calf in the right corner is rubbing her chin at the iron bar and wooden demarcation while establishing eye contact with the fieldworker, as shown in Picture 11.2.

Both pictures also show that in the second section of the barn four cows are standing on their feet whereas two cows are lying down in cubicle divisions. The calf to the right in Picture 11.2 was headbutted by another for about two seconds when trying to move over to the most right-hand section of the barn (not visible in the picture). Picture 11.3, however, shows calves in section 2 mirroring each other's body positions when lying down in the cubicles. Although their bodies do not touch and they are not able to lie down in a circle as less restrictive settings, they are able to choose to lie down all together in the same way at the same time. The two calves in the cubicles in the back are facing each other whereas the two shown in the foreground

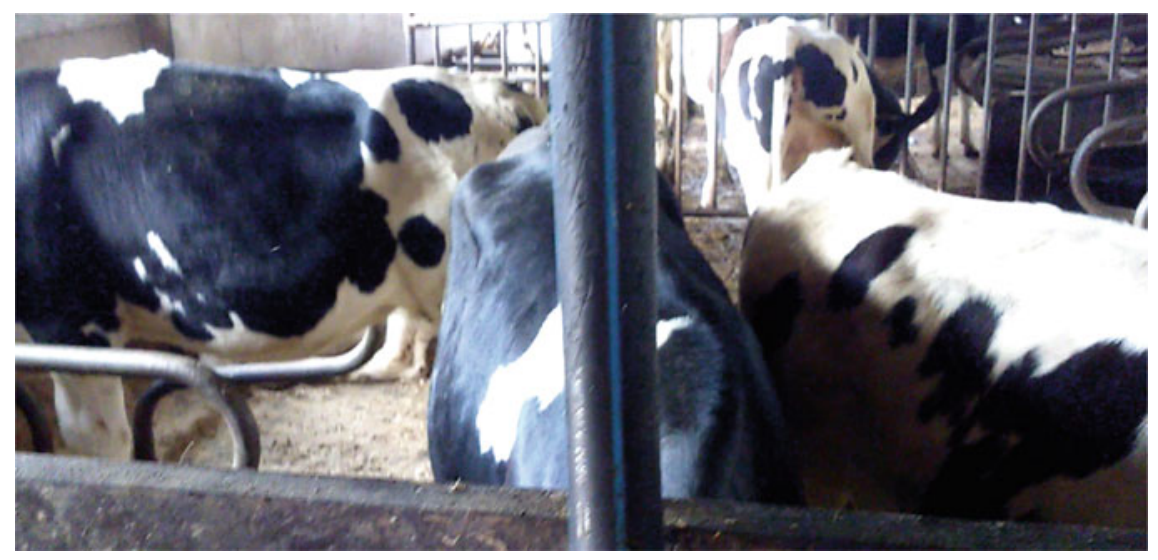

Picture 11.1 Standing in the jongveestal (Farm 1, 17 August 2018) 


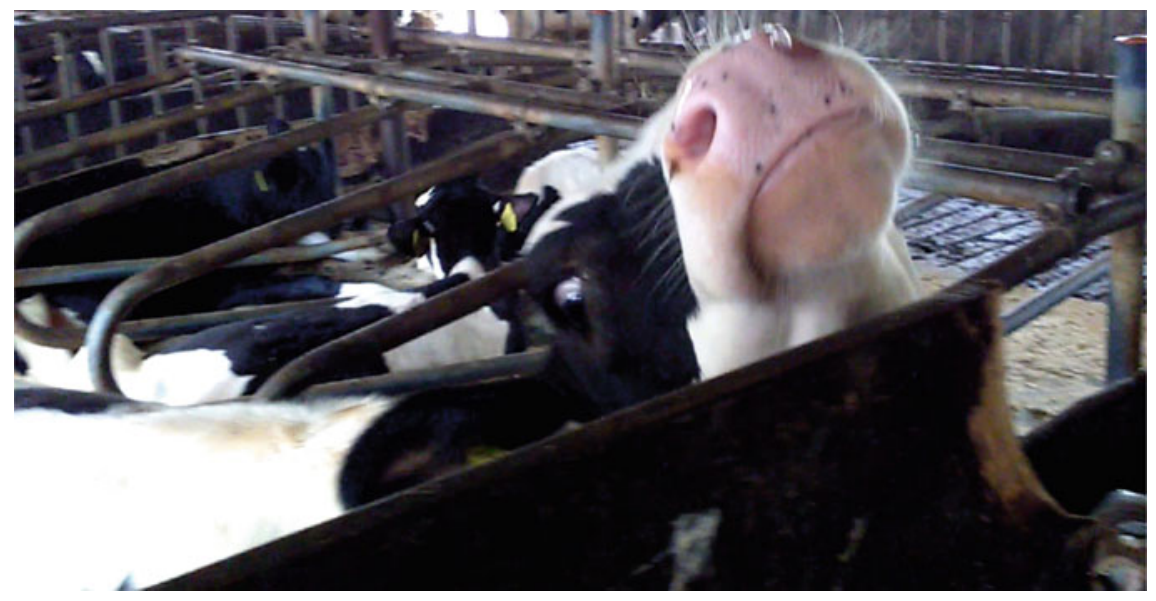

Picture 11.2 Calf is rubbing her chin at the fence while establishing eye contact with the fieldworker (Farm 1, 17 August 2018)

do not. Note that the younger calf in section 1 has decided to look out of the window instead of synchronizing with the others.

As a material-semiotic resource, bodily synchronizing can be seen as part of what Frans de Waal has described as "identification" with the other, a process of "bodily mapping the self onto the other (or the other onto the self)" which not only relates to a capacity for shared neural representation, but also forms "a precondition for imitation and empathy" (De Waal 2012, 123). During the fieldwork, a clear practice of bodily synchronizing - which we consider here as a social form of meaning-making typical for encaged dairy cows-emerged during the communicative event of feeding (by the farmer) and eating (by the cows). The farmer feeds the calves twice a day by putting upside down a wheelbarrow loaded with food on the ground before them. An iron feed fence separates the human and nonhuman animals during this event while at the same time it mediates the meanings that arise from their mutual interaction. The farmer provides the food from one side of the fence whereas the calves on the other side need to position themselves before individual openings and put their heads through the bars in order to reach the food below. Since there are only as many openings as calves, every individual has to touch her neighbor to secure a place (see Pictures $11.4 \mathrm{a}, \mathrm{b}$ ).

As the calves put their heads through the iron bars they simultaneously bow their heads forward and downward to pick up the food from the ground, taking a slightly more upward head position in order to chew. Within this joint "embodiment of movement," a collective form of sociality in which each calf will instantaneously "follow and lead" (Argent 2012, 120), ${ }^{11}$ the calves engage one another and the space around them in bodily acts of identification that articulate the jongveestal as a shared social place. Thus, although for encaged calves feeding is clearly a habitual and

\footnotetext{
${ }^{11}$ Argent writes about synchronizing between horses and riders.
} 


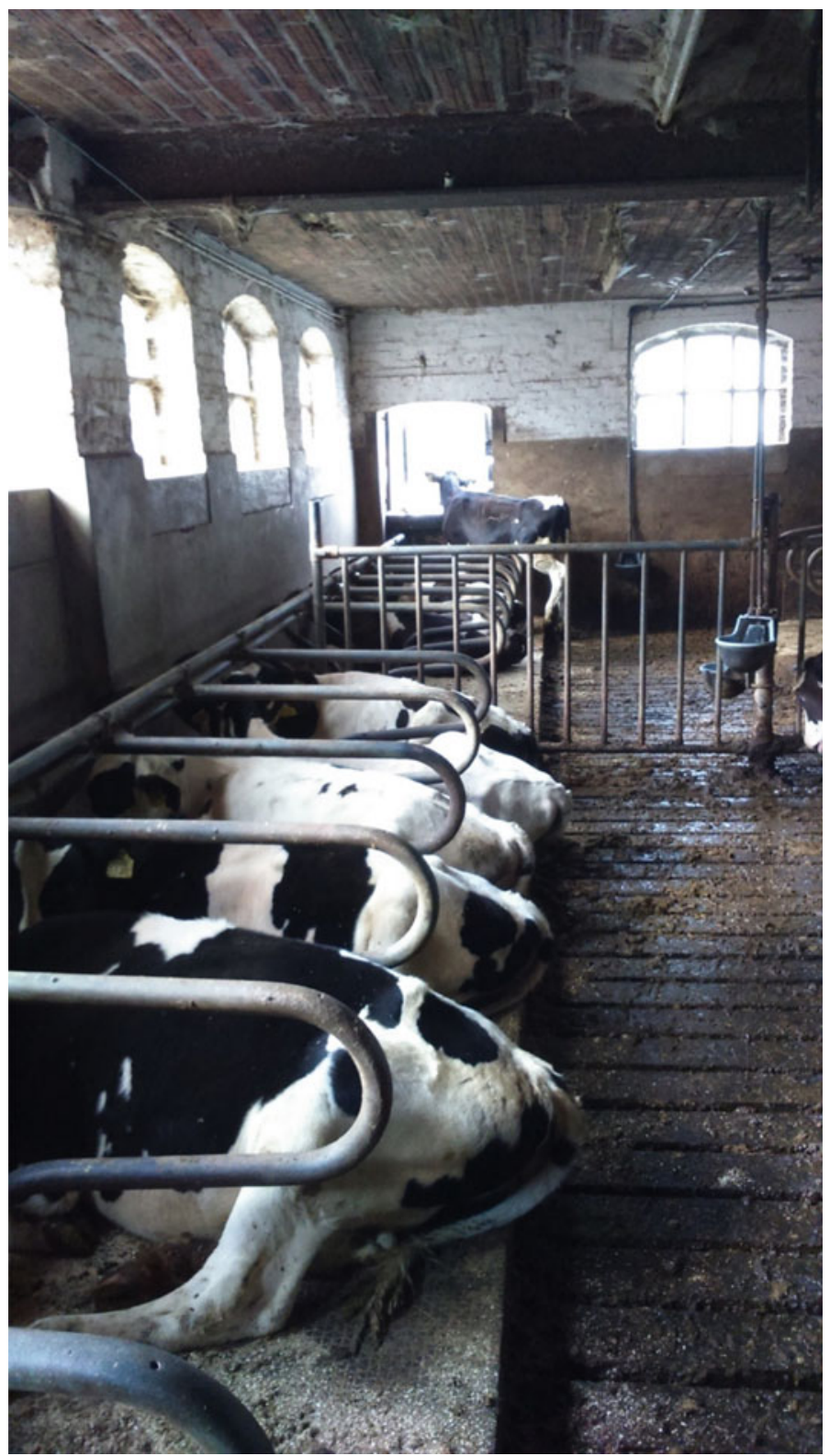

Picture 11.3 Bodily synchronizing in cubicle divisions in the jongveestal (Farm 1, 17 August 2018) 
a

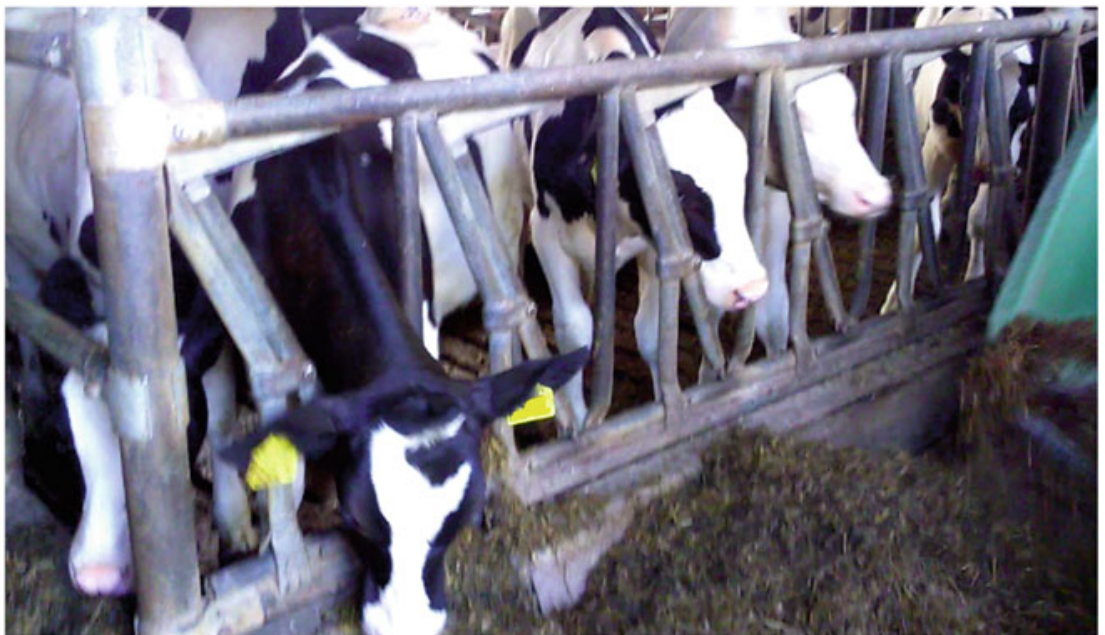

b

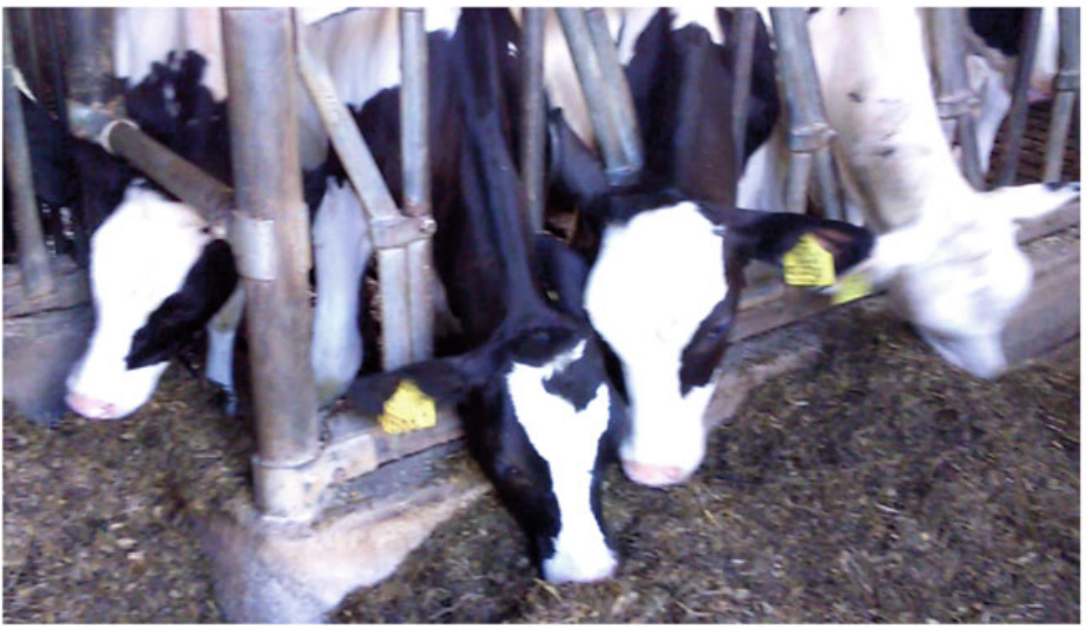

Picture 11.4 a The calves positioning themselves at the feed fence (wheelbarrow on the right); b The calves are synchronizing during their eating practice

routinized practice, from a sociolinguistic perspective it also entails creative acts of place-making through what Argent calls "kinesic, haptic, and proxemic communication modes" (Argent 2012, 119). The synchrony of movement that occurs in and through the spacing of interactional distances not only orients calves to group living, but also enables them to imbue their restricted environment with meaning in the form of social bonding and thus constitute themselves as linguistic agents.

Specifically, we argue that nonhuman practices of place-making in an intensive dairy farm can be seen as a form of bi- or multilingualism peculiar to the context of industrial animal production. The iron bars make sound when the synchronizing calves put their heads through them and move their faces up and down in co-motion 
to reach for the food on the ground during eating practice. These sounds are not meaningless or arbitrary but constitute a semiotic resource for calves to reinforce social bonding, specifically since the sounds of the iron bars and bodies co-shape each other acoustically. Eating practices in the jongveestal, then, are acts of placemaking where calves do not only use their vocal tract to produce language, but also establish themselves as linguistic beings through the rhythmic clattering of the iron bars that shapes the synchronizing bodies into socially meaningful sounds. In other words, these calves engage in a process of nonhuman place-making not only by producing one language with their own bodies, that is, the words or vocalizations for "greeting" and "hunger" which are inextricably combined with multimodal and multisensory ways of meaning-making through body positioning and visual, auditory, olfactory, gustatory and tactile practices, but also by producing a second language with the material-semiotic means that both compose and transcend their restricted environment.

Being socialized into the environment of an industrial dairy farm, then, for cows implies being or becoming bilingual, where bilingualism is to be understood as a "complex set of practices" (Heller 2007, 15) which draw on linguistic resources that belong to two codes which are structurally maximally divergent (see Auer, forthcoming, 8), in this case one code produced by vocal tract and one code produced by synchronizing bodies and iron bars. The latter language is more context-dependent than the former because of its restriction to the practice of feeding in conditions of captivity. These two codes thus reveal structural constraints in the linguistic sense: they can combine together in a multimodal way but cannot be mixed. The observations do not show that calves alternate between the two codes within one single discourse - the social practice of eating together-even if both codes are part of the broader material-semiotic assemblage through which place-making is established. In the sociolinguistic framework, the two codes might be said to correspond to different social functions and identities, since different languages, or language varieties, are associated with diverging "processes of construction of social difference and social inequality" (Heller 2007, 15). The "bars and bodies" code will be associated primarily with encaged individuals, suggesting that this form of bilingualism is specific to the complex network of connections among human and nonhuman agents that constitutes daily life at an intensive dairy farm.

Crucially, the material presence of the feed fence, which both enables and constrains the expression of linguistic agency in this context, should be understood not merely as a demarcation of physical space, but as belonging to the spatial repertoire through which language is produced as a "distributed effect of a range of interacting objects, people and places" (Pennycook 2017, 278). As an embodied and embedded practice, linguistic place-making in the jongveestal is thus not simply a conditioned response to an unresponsive environment, nor does it arise from the individual communicative competence of calves and heifers; rather, it emerges from within a complex assemblage of material-semiotic resources distributed across human and nonhuman subjects, artefacts and environments, including the means of confinement by which humans seek to restrict the freedom of other animals. In other words, the conditions of captivity in an intensive dairy farm are not external but 
intrinsic to how cows engage in acts of place-making that we, in Heideggerian terms, might understand as linguistic practices of world-formation. This view, as we will conclude, has significant consequences for how we may conceptualize the expression of nonhuman animal agency, in particular linguistic agency, in the troubling context of the Anthropocene.

\subsection{Conclusion}

From a traditional humanist perspective, domesticated captive animals are doubly barred from entering into a meaningful relationship with the world: not only are nonhuman animals, in this view, by nature captivated in their environment (as Heidegger and many others have suggested), it is also assumed that confinement in cages does nothing but further limit their natural instincts and capabilities. This view effectively renders nonhuman animals, cows in particular, mute and dumb, while at the same time it reinforces a traditional mechanistic worldview where both nature and matter are considered to be passive and inert, available for manipulation by humans and exploitable for profit (Merchant 1992, 48-55). The critically posthumanist perspective developed in this chapter, by contrast, not only acknowledges cows as the social and intelligent speaking beings that they are, but also approaches their material encagement - the bars and fences meant as barriers to prevent calves and heifers from freely going wherever they want-as a social and spatial artefactual resource for building a meaningful world. Paradoxically, then, it is their state of unfreedom that allows dairy cows to open up the restricted environment of industrial animal farming, exemplified here by the young cattle barn, as a linguistically meaningful place.

In drawing attention to the linguistic agency of dairy cows, we do not wish to reiterate the familiar observation that "agency is intrinsic to the way animals behave" (Špinka and Wemelsfelder 2011, 34), nor are we suggesting that the capacity of captive animals to act is somehow "expanded" or "curtailed" through acts of linguistic place-making. In the context of industrial dairy farming, where categorical boundaries between humans and other animals, as well as between organisms and machines, have collapsed-a condition exemplifying the "implosion of nature and culture" (Haraway 2003, 16) that marks the Anthropocene-neither agency nor language can be understood as a property of individual persons or collectivities. Rather, we must account for how different forms of agency, including linguistic agency, emerge from within what political theorist Jane Bennett $(2010$, 107) has called "agentic assemblages," that is, networks of human and nonhuman actors living together in relations of systemic inequality. In this chapter, therefore, we have tried to show how a non-anthropocentric approach to linguistic place-making, understood as a practice of more-than-human sociality, can help us reckon with the question of nonhuman animal agency in new ways.

Assemblages, as Pennycook $(2017,278)$ notes, "describe the way things are brought together and function in new ways" and as such they provide a way of 
thinking about agency as a distributed force, much like we described language and cognition as spatially distributed. Bennett, indeed, suggests that we think of agency as "distributed across an ontologically heterogeneous field, rather than being a capacity localized in a human body or in a collective produced (only) by human efforts" (Bennett 2010, 23). Linguistic agency, then, is not an individual or collective competence that can be "mastered" or "possessed" but should rather be seen as a processually emergent quality arising from multiple assemblages of human and nonhuman elements, including material things, artefacts and spaces. This conception of agency, rooted in what Bennett (2010) calls a "vital materialism" and what Pennycook (2018) describes as a "posthumanist applied linguistics," disturbs the traditional understanding of agency as the capacity for self-willed action, linked especially to human subjectivity and intentionality, as well as the corollary presumption that the more-than-human material world-including other animals and the physical environment-is essentially passive, inert and predetermined in its operations.

Throughout this chapter, we have sought to demonstrate the usefulness of a nonanthropocentric approach to language and language practices in light of a long history of human exceptionalism that has routinely denied nonhuman animals the freedom and ability to speak. We have elaborated a posthumanist conception of language as a distributed effect of multiple interacting bodies in order to foreground the fluidity through which a cow, a calf, calves, a wheelbarrow, a farmer, an iron feed fence, a lock, the clattering of bars, sounds of chewing, sounds of puffing, sounds of urinating, the smell of food, urine, feces, other bodies in proximity or distance, movements up and down, become relationally entangled with one another and, crucially, with the anthropological machine of industrial animal production. Furthermore, we have shown how rethinking nonhuman animal agency in terms of material-semiotic assemblages, as an equally distributed effect of linguistic interactions and social processes, allows us to break away from the idea of lifeless matter, including the Cartesian understanding of nonhuman animals as mindless machines, an idea which has shaped the pervasive modes of human exceptionalism and instrumentalism that have traditionally characterized the humanist agenda and which continue to inform ideas about the "muteness" and "bruteness" of nonhuman creatures today. In this way, we hope to contribute to a greater recognition among humans of other animals, not only as sentient living beings, but as intelligent, social, speaking beings, linguistic agents who even under poor conditions form rich and complex relationships with the world to make it a meaningful place.

Acknowledgements The first author is very grateful to the participating farmer for all support, the opportunity to make recordings, and time. 


\section{References}

Agamben, G. 2004. The open: Man and animal. Stanford: Stanford University Press.

Argent, G. 2012. Toward a privileging of the nonverbal: Communication, corporeal synchrony, and transcendence in humans and horses. In Experiencing animal minds: An anthology of animalhuman encounters, ed. J.A. Smith and R.W. Mitchell, 111-128. New York: Columbia University Press.

Århem, K. 1998. Powers of place: Landscape, territory and local belonging in Northwest Amazonia. In Locality and belonging, ed. N. Lovell, 78-102. London and New York: Routledge.

Auer, P. forthcoming. "Translanguaging" or "doing languages"? Multilingual practices and the notion of "codes". In Language(s): Multilingualism and it consequences, ed. J. MacSwann. Bristol: Multilingual Matters. Retrieved from https://www.researchgate.net/publication/332 593230_'Translanguaging'_or_'doing_languages'_Multilingual_practices_and_the_notion_of_ 'codes'.

Bennett, J. 2010. Vibrant matter: A political ecology of things. Durham and London: Duke University Press.

Bergeron, R., A.J. Badnell-Waters, S. Lambton, and G. Mason. 2006. Stereotypic oral behaviour in captive ungulates: Foraging, diet and gastrointestinal function. In Stereotypic animal behaviour: Fundamentals and applications to welfare, 2nd ed., ed. G. Mason and J. Rushen, 19-57. Wallingford and Cambridge: CABI.

Berwick, R.C., and N. Chomsky. 2016. Why only us: Language and evolution. Cambridge and London: The MIT Press.

Bucholtz, M., and K. Hall. 2016. Embodied sociolinguistics. In Sociolinguistics: Theoretical debates, ed. N. Coupland, 173-197. Cambridge: Cambridge University Press.

Chomsky, N. 2002. On nature and language. Cambridge: Cambridge University Press.

Chomsky, N. 2006. Language and mind, 3rd ed. Cambridge: Cambridge University Press.

Colvin, C.M., K. Allen, and L. Marino. 2017. Thinking cows: A review of cognition, emotion, and the social lives of domestic cows. https://www.farmsanctuary.org/wp-content/uploads/2017/10/ TSP_COWS_WhitePaper_vF_web-v2.pdf.

Cornips, L. 2019. The final frontier: Non-human animals on the linguistic research agenda. Linguistics in the Netherlands 36 (1): 13-19.

Cornips, L., and F. Gregersen. 2016. The impact of Labov's contribution to general linguistic theory. Journal of Sociolinguistics 20 (4): 498-524. https://doi.org/10.1111/josl.12197.

Cornips, L., and V. de Rooij (eds.). 2018a. The sociolinguistics of place and belonging: Perspectives from the margins. Amsterdam: John Benjamins.

Cornips, L., and V. de Rooij. 2018b. Introduction: Belonging through linguistic place-making in center-periphery constellations. In The sociolinguistics of place and belonging: Perspectives from the margins, ed. L. Cornips and V. de Rooij, 1-16. Amsterdam: John Benjamins.

Cornips, L., and M. van Koppen. 2019. Embodied grammar in Dutch dairy cows. Poster presented at the workshop Animal Linguistics: Take the Leap!, L'École normale supérieure, Paris, June 17.

Cottingham, J. 2008. Cartesian reflections: Essays on Descartes' philosophy. Oxford: Oxford University Press.

Cowley, S.J. 2011. Distributed language. Amsterdam: John Benjamins.

Cull, L. 2015. From homo performans to interspecies collaboration: Expanding the concept of performance to include animals. In Performing animality: Animals in performance practices, ed. L. Orozco and J. Parker-Starbuck, 19-36. Basingstoke: Palgrave Macmillan.

De Waal, F. 2012. A bottom-up view of empathy. In The primate mind: Built to connect with other minds, ed. F. de Waal and P.F. Ferrari, 121-138. Cambridge and London: Harvard University Press.

Derrida, J. 2009. The beast and the sovereign: Volume 1, trans. G. Bennington. Chicago and London: University of Chicago Press. 
Descartes, R. 1985. Discourse on the method. In The philosophical writings of Descartes: Volume 1, trans. J. Cottingham, R. Stoothoff, and D. Murdoch, 111-175. Cambridge: Cambridge University Press.

Despret, V. 2008. The becomings of subjectivity in animal worlds. Subjectivity 23: 123-139. https:// doi.org/10.1057/sub.2008.15.

Evans, V. 2014. The language myth: Why language is not an instinct. Cambridge: Cambridge University Press.

Hagen, K., and D.M. Broom. 2004. Emotional reactions to learning in cattle. Applied Animal Behaviour Science 85: 203-213.

Haraway, D. 2003. The companion species manifesto: Dogs, people, and significant otherness. Chicago: Prickly Paradigm Press.

Haraway, D. 2008. When species meet. Minneapolis and London: University of Minnesota Press.

Harrison, P. 1992. Descartes on animals. The Philosophical Quarterly 42 (167): 219-227. https:// doi.org/10.2307/2220217.

Hauser, M.D., N. Chomsky, and W.T. Fitch. 2002. The faculty of language: What is it, who has it, and how did it evolve? Science 298 (5598): 1569-1579. http://dx.doi.org/10.1126/science.298. 5598.1569.

Heidegger, M. 1971. Poetry, language, thought, trans. A. Hofstadter. New York: Harper \& Row.

Heidegger, M. 1995. The fundamental concepts of metaphysics: World, finitude, solitude, trans. W. McNeill and N. Walker. Bloomington and Indianapolis: Indiana University Press.

Heller, M. 2007. Bilingualism as ideology and practice. In Bilingualism: A social approach, ed. M. Heller, 1-22. Basingstoke: Palgrave Macmillan.

Jahns, G. 2013. Computational intelligence to recognize animal vocalization and diagnose animal health status. In Computational intelligence in intelligent data analysis, ed. C. Moewes and A. Nürnberger, 239-249. Berlin: Springer.

Johnstone, B. 2011. Language and place. In The Cambridge handbook of sociolinguistics, ed. R. Mesthrie, 203-217. Cambridge: Cambridge University Press. https://doi.org/10.1017/CBO978 0511997068.017.

Kulick, D. 2017. Human-animal communication. Annual Review of Anthropology 46: 357-378. https://doi.org/10.1146/annurev-anthro-102116-041723.

Labov, W. 1994. Principles of linguistic change. Volume 1: Internal factors. Oxford and Cambridge: Blackwell.

Labov, W. 2001. Principles of linguistic change. Volume 2: Social factors. Oxford and Cambridge: Blackwell.

Marino, L., and K. Allen 2017. The psychology of cows. Animal Behavior and Cognition 4 (4): 474-498. https://dx.doi.org/10.26451/abc.04.04.06.2017.

McLennan, K.M. 2013. Social bonds in dairy cattle: The effect of dynamic group systems on welfare and productivity. Doctoral thesis, The University of Northampton. http://nectar.northampton.ac. $\mathrm{uk} / 6466 /$.

Meijer, E. 2016. Speaking with animals: Philosophical interspecies investigations. In Thinking about animals in the age of the Anthropocene, ed. M. Tønnessen, K. Armstrong Oma, and S. Rattasepp, 73-88. Lanham: Lexington Books.

Meijer, E. 2019. Animal languages: The secret conversations of the natural world. London: John Murray.

Merchant, C. 1992. Radical ecology: The search for a livable world. London and New York: Routledge.

Moran, J., and R. Doyle. 2015. Cow talk: Understanding dairy cow behavior to improve their welfare on Asian farms. Melbourne: CSIRO Publishing. http://www.publish.csiro.au/ebook/7929.

Müller, C., J. Bressem, and S.H. Ladewig. 2013. Towards a grammar of gestures: A form-based view. In Body-Language-Communication: An international handbook on multimodality in human interaction, ed. C. Müller, A. Cienki, E. Fricke, S.H. Ladewig, D. McNeill, and S. Tessendorf, 707-733. Berlin and Boston: De Gruyter Mouton. 
Nawroth, C., J. Langbein, M. Coulon, V. Gabor, S. Oesterwind, J. Benz-Schwarzburg, and E. von Borell. 2019. Farm animal cognition: Linking behavior, welfare and ethics. Frontiers in Veterinary Science 6 (24): 1-16. https://doi.org/10.3389/fvets.2019.00024.

Padilla de la Torre, M., E.F. Briefer, T. Reader, and A.G. McElligott. 2015. Acoustic analysis of cattle (Bos taurus) mother-offspring contact calls from a source-filter theory perspective. Applied Animal Behaviour Science 163: 58-68. http://dx.doi.org/10.1016/j.applanim.2014.11.017.

Peck, A., C. Stroud, and Q. Williams (eds.). 2019. Making sense of people and place in linguistic landscapes. London and New York: Bloomsbury.

Pennycook, A. 2016. Posthumanist applied linguistics. Applied Linguistics 39 (4): 445-461. https:// doi.org/10.1093/applin/amw016.

Pennycook, A. 2017. Translanguaging and semiotic assemblages. International Journal of Multilingualism 14 (3): 269-282. https://doi.org/10.1080/14790718.2017.1315810.

Pennycook, A. 2018. Posthumanist applied linguistics. London and New York: Routledge.

Pennycook, A., and E. Otsuji. 2015. Making scents of the landscape. Linguistic Landscape 1 (3): 191-212. https://doi.org/10.1075/11.1.3.01pen.

Schieffelin, B.B. 2018. Language socialization and making sense of place. In The sociolinguistics of place and belonging: Perspectives from the margins, ed. L. Cornips and V. de Rooij, 27-54. Amsterdam: John Benjamins.

Špinka, M., and F. Wemelsfelder 2011. Environmental challenge and animal agency. In Animal welfare, 2nd ed., ed. M.C. Appleby, J.A. Mench, I.A.S. Olsson, and B.O. Hughes, 27-43. Wallingford and Cambridge: CABI.

Vallez, T. 2013. Huisvesting van jongvee op een melkveebedrijf. Master thesis, Ghent University. https://lib.ugent.be/fulltxt/RUG01/002/062/712/RUG01-002062712_2013_0001_AC.pdf.

Wilkie, R.M. 2010. Livestock/deadstock: Working with farm animals from birth to slaughter. Philadelphia: Temple University Press.

Leonie Cornips is senior researcher at the NL-Lab, Humanities Cluster (KNAW) in Amsterdam and professor Languageculture in Limburg at Maastricht University, the Netherlands. Her research deals with sociolinguistic issues. Current topics are national and regional identity construction through language practices, bidialectal child acquisition, multilingualism and intra- and interspecies interactions, in particular, dairy cow language and communication. She received her Ph.D. from the University of Amsterdam. Her homepage is https://pure.knaw.nl/portal/en/persons/l-cor nips/publications/.

Louis van den Hengel is Assistant Professor of Gender and Diversity Studies at Maastricht University, the Netherlands. His research deals with the potentiality of contemporary art performances for activating new socio-political imaginaries and for envisioning an affirmative ethics of difference for the twenty-first century. In other words, he is interested not only in how performance negotiates new relationships between contemporary art and the cultural politics of gender, sexuality, race, class, and species difference, but also in how it may help actualize new modalities of being in, and becoming with, the world. His most recent publications include contributions to journals such as Criticism: An Interdisciplinary Quarterly and to edited volumes such as Doing Gender in Media, Art and Culture (Routledge, 2018) and Entanglements and Weavings: Diffractive Approaches to Gender and Love (Brill, 2021). 
Open Access This chapter is licensed under the terms of the Creative Commons Attribution 4.0 International License (http://creativecommons.org/licenses/by/4.0/), which permits use, sharing, adaptation, distribution and reproduction in any medium or format, as long as you give appropriate credit to the original author(s) and the source, provide a link to the Creative Commons license and indicate if changes were made.

The images or other third party material in this chapter are included in the chapter's Creative Commons license, unless indicated otherwise in a credit line to the material. If material is not included in the chapter's Creative Commons license and your intended use is not permitted by statutory regulation or exceeds the permitted use, you will need to obtain permission directly from the copyright holder.

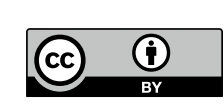

